\title{
PENGEMBANGAN POTENSI DIRI MELALUI METODE DZIKIR DAN OLAH NAPAS \\ (PENELITIAN PADEPOKAN PERISAI BATHIN DAN SILAT LADUNI DI KAB. BANDUNG BARAT)
}

\author{
Anwar Supenawinata \\ UIN Sunan Gunung Djati Bandung, Jl. A.H. Nasution 105 \\ e-mail:anwar.supenawinata@gmail.com
}

\begin{abstract}
Every human being has potencies that needs to be empowered, which is the element of earth, fire, water, and air. Basically these elements consist of two aspects, namely, inner aspects what we called the soul and outer aspects that is the body. Elements of the inner aspects which are water, fire and air, while an element of the outer aspect is land. To process the four elements, it's required struggle and continuous training so that it could benefit themselves, especially in the implementation of worship, as well as beneficial to others.
\end{abstract}

Keywords: potencies, inner-aspect, outer-aspect, worship.

\begin{abstract}
Abstrak
Setiap manusia memiliki potensi diri yang perlu diberdayakan, yang merupakan unsur tanah, api, air, dan udara. Pada dasarnya unsur-unsur tersebut terdiri dari dua aspek yaitu, aspek dalam yang disebut jiwa dan aspek luar yang disebut dengan raga. Unsur pada aspek dalam yaitu air, api dan udara sedangkan unsur pada aspek luar yaitu tanah. Untuk mengolah keempat unsur tersebut diperlukan perjuangan dan latihan secara kontinu sehingga dapat bermanfaat bagi diri sendiri khususnya dalam pelaksanaan ibadah, maupun bermanfaat bagi orang lain.
\end{abstract}

Kata kunci: potensi, aspek dalam, aspek luar, ibadah

\section{PENDAHULUAN}

Banyak macam jenis dzikir dan membaca al-Qur'an yang dilakukan oleh Umat Islam banyak ragam, seperti dzikir biasanya hanya lapadznya saja yang diucapkan tanpa dibarengi dengan cara bernapas yang baik. Jenis berdzikir yang banyak dibaca antara lain tasbih, tahlil, tahmid, istighfar yang merupakan lapadz dzikrullah (mengingat Allah) dan membaca al-Qur'an dengan tartil (mahrad dan tajwid). Ketika mengucapkan lapadz dzikrullah yang baik adalah dengan olah napas. ${ }^{1}$

Dzikir mengingat Allah keadaannya jauh berbeda. Bangun tidur yang pertama diingatnya adalah Allah, ketika makan, keluar rumah, berjalan, bekerja, kembali ke rumah hingga mau tidur yang diingat hanyalah Allah. Ia selalu melibatkan Allah

\footnotetext{
${ }^{1}$ A. Asep berpendapat bahwa ketika berdzikir harus dibarengi dengan olah napas yang baik
}

dalam setiap aktifitasnya. Hatinya selalu berdialog dengan Allah mohon petunjuk dan bimbingan menghadapi berbagai masalah yang silih berganti datang dan pergi dari dirinya. Hatinya nyaman dan tentram dengan mengingat Allah, apapun masalah yang datang dihadapinya dengan tenang. Urusan dunia tidak membuatnya panik, stres, cemas atau gelisah, ia menghadapi semua itu bersama Allah. Hati mereka selalu dibimbing oleh Allah sehingga mereka bisa membedakan yang hak dan yang bathil. Allah membimbing hati dan pikirannya menyelesaikan berbagai masalah, sehingga hidup terasa ringan dan mudah.

Berdzikir mengingat Allah dengan mengulang mengucapkan kalimat thoyyibah seperti istighfar, tahlil, tahmid, tasbih dan membaca Al-Qur'an. Namun ada beberapa kendala yang dirasakan sehingga tidak bisa melakukan kegiatan 
tersebut secara rutin dalam waktu yang cukup lama. Kendala yang dihadapi antara lain rasa bosan, mengatuk, kaki semutan dan lain sebagainya. Menggabungkan kegiatan olah napas dengan dzikrullah dapat menghilangkan berbagai kendala tersebut diatas, olah napas atau menghirup udara yang bersih pada waktu pagi hari karena udaranya masih segar dan bertujuan untuk menghilangkan udara basi yang berada dalam tubuh dan memasukkan udara yang bersih dan segar tadi berguna sebagai kesehatan ${ }^{2}$.

\section{RUMUSAN MASALAH}

Uraian di atas menunjukan bahwa dalam kegiatan berdzikir perlu dibarengi dengan olah napas secara sempurna yang pernah dilakukan oleh Perguruan Perisai Bathin (Silat Laduni) dengan metode tertentu yang bisa mengungkap potensi diri dan sebagai kebutuhan hidup terutama untuk kesehatan lahir bathin. Karena itu masalah pokok yang muncul agar lebih mudah dan lebih terarah dalam melaksanakan penelitian disini dikemukakan pertanyaan-pertanyaan.

1. Apa yang melatarbelakangi pengembangan terhadap metode dzikir dan olah napas di padepokan perisai bathin?

2. Apa tujuan padepokan perisai bathin dalam mengembangkan metode dzikir dan olah napas?

3. Bagaimana pelaksanaan metode dzikir dan olah napas yang dilakukan oleh padepokan perisai bathin?

4. Kebutuhan apa saja yang diperlukan dalam metode dzikir dan olah napas pada pengembangan potensi diri manusia?

5. Apa saja hikmah (rahasia) yang terkandung dalam pelaksanaan metode dzikir dan olah napas?

\section{KERANGKA PEMIKIRAN}

Konsep untuk merumuskan tentang manusia menurut Hanna Djumhana Bastaman (1993) memberi contoh antara lain dari riwayat Nabi Adam a.s., yaitu (1)

\footnotetext{
${ }^{2}$ A. Yuli pimpinan Padepokan Perisai Bathin.
}

Manusia mempunyai derajat sangat tinggi sebagai khalifah Allah, (2) Manusia tidak menanggung dosa asal atau dosa turunan, (3) Manusia merupakan kesatuan dari empat dimensi : fisik-biologi, mentalpsikis, sosio-kultural dan spiritual, (4) Dimensi spiritual (Ruhani, Ruh-Ku) memungkinkan manusia mengadakan hubungan dan mengenal Tuhan melalui cara-cara yang diajarkan-Nya, (5) Manusia memiliki kebebasan berkehendak (freedom of will) yang memungkinkan manusia untuk secara sadar mengarahkan dirinya ke arah keluhuran atau kearah kesesatan, (6) Manusia memiliki akal sebagai kemampuan khusus dan dengan akalnya itu mengembangkan ilmu dan teknologi serta peradaban, (7) Manusia tak dibiarkan hidup tanpa bimbingan dan petunjuk-Nya.

Tugas manusia di dunia sebagai Abdullah (hamba Allah) dan sebagai khalifah, maka manusia dilengkapi dengan potensi (sejumlah ciri) yang meliputi : raga, fitrah, ruh, kebebasan berkehendak, akal, nafsu ${ }^{3}$. Sedangkan menurut Ibin Kutibin Tadjudin bahwa Ruh, Nafs, Qolbu, Af'idah (Fuad), Jiwa, Akal, Psikis, Mental, Hati nurani, perasaan dan pikiran adakalanya mempunyai pengertian yang sama tetapi adakalanya diberi pengertian yang dihubungkan dengan fungsi, misalnya kalau dihubungkan dengan perasaan yang halus suka dipakai istilah Qolbu atau hati nurani, dikatakan jiwa kalau mencakup pengertian yang luas dari semua aspek kehidupan, akal apabila dihubungkan dengan kecerdasan. Mental lebih cenderung dihubungkan pada pembahasan yang bersifat lebih umum ada hubungannya dengan kemampuan intelegensia, kemampuan akal yang dihubungkan dengan emosi ${ }^{4}$.

Setiap manusia mencari jalan
menuju ke tempat tujuan yaitu
kebahagiaan, dengan segala daya upaya

\footnotetext{
${ }^{3}$ Djamaludin Ancok dan Fuad Nashori Suroso Psikologi Islami, Yogyakarta,2011. halaman 152159, Pustaka Pelajar

${ }^{4}$ Ibin Kutibin Tadjudin, Psikoterapi Holistik Islami, halaman 52, Kutibin Bandung, 2007.
} 
dan sarana yang ada pada masing-masing manusia, yang telah dianugrahkan Allah. Menurut Muhammad Abduh dalam tafsir Al-Qur'anul Hakim (tafsir Al-Manar) daya dan sarana yang dipunyai manusia digunakan sebagai senjata untuk mencapai tujuan dalam ilmu agama disebut hidayah sebagai senjata hidup antara lain: (1) insting (hidayah ghariziah), (2) Pancaindra (hidayah Hawasiyah), (3) Akal (hidayah Aqliyah), (4) agama (hidayah Diniyah) 5 .

Hakikat manusia dalam menjalani hidup berada pada lima zaman atau alam, yaitu (1) alam ruh, (2) alam rahim (3) alam dunia (4) alam barzakh (5) alam akhirat. Menurut Syukriadi Sambas bahwa perilaku lahir manusia pada hakikatnya merupakan ekspresi dan aktualisasi dari perilaku potensi nafs (jiwa) yang memposisikan manusia ke arah posisi baik dan benar dan ke arah posisi jelek dan salah. Potensi nafs tersebut diinformasikan oleh al-Qur'an terdapat empat macam yaitu : (1) nafs muthmainnah (Q.S al-Fajr 89: 27-28), (2) Nafs mulhamah/supiah (Q.S al-Syams 91 : 7-10), (3) nafs amarah (Q.S $12: 53$ ), (4) nafs lawamah (Q.S alQiyamah 75 :2). Nafs (1) dan (2) merupakan bagian dari potensi syahwat, sedangkan nafs (3) dan (4) merupakan bagian ghadhab yang merupakan potensi pokok. Nafs sebagai potensi ruhaniyah (nafs mulhamah/supiah) manusia memiliki hubungan pengaruh dengan aspek unsur asal bahan kejadian fisik (jasad), yaitu unsur ardl (tanah), ma (air), hawa (udara) dan nar (api). Keempat unsur ini mempengaruhi secara berpasangan terhadap empat macam nafs yang menimbulkan karakter dan kecenderungan perilaku manusia ${ }^{6}$.

Manusia diberi kebebasan untuk memilih tingkah lakunya sendiri, kebaikan atau keburukan. Sebagai khalifah

\footnotetext{
${ }^{5}$ Rachmat Djatnika, Sistem Etika Islami (Akhlak Mulia), Halaman 18, Pustaka Panjimas, Jakarta, 1996.

${ }^{6}$ Agus Ahmad Safei, Memimpin dengan Hati yang Selesai, Jejak Langkah dan Pemikiran Baru

Dakwah. Halaman 155, Pustaka Setia, 2003.
}

manusia menerima dengan kemauan sendiri amanah yang tidak dapat dipikul oleh makhluk-makhluk lain. Sebagaimana firman Allah SWT. "Dan katakanlah kebenaran itu datangnya dari Tuhanmu; Maka Barang siapa yang ingin (beriman) hendaklah ia beriman, dan Barangsiapa yang ingin (kafir) Biarlah ia kafir". (QS Al-Kahfi ayat 29)

Manusia juga dapat merubah pada dirinya dengan kemauan yang dimilikinya sebagai mana Firman Allah Swt, 'Sesungguhnya Allah tidak merobah Keadaan sesuatu kaum sehingga mereka merobah keadaan yang ada pada diri mereka sendiri'. (QS. Surat Ar-Ra'd ayat 11)

Untuk lebih jelasnya lagi dapat dilihat pada kerangka pikir berikut ini.

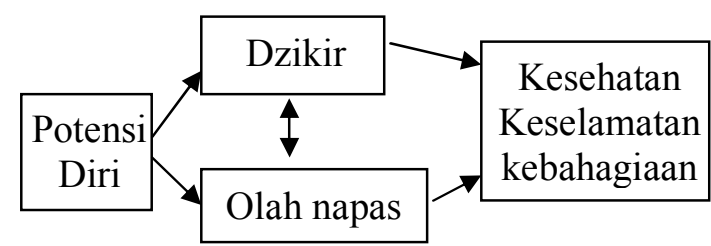

\section{Keterangan:}

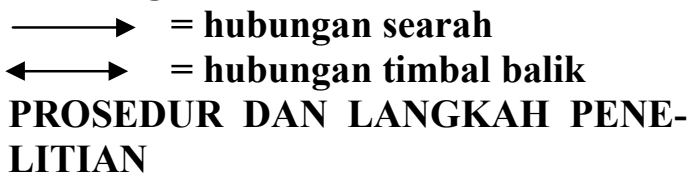

\section{LITIAN}

A. Metode Penelitian

Metode penelitian ini menggunakan metode kualitatif atau naturalistik yang mengedepankan berbagai masalah di Padepokan Perisai Bathin terutama asal usul pendirian padepokan dan peserta yang mengikutinya sampai saat ini. bersifat sewajarnya atau seadanya yang nyata dalam aspek kehidupan di padepokan tersebut.

B. Lokasi Penelitian

Lokasi penelitian yaitu bertempat di Padepokan Perisai Bathin Kampung Babakan Muncang RT. 01 RW 12 Kecamatan Cisarua Kabupaten Bandung Barat. Dan di Kampung Hegarmanah Citapen Kecamatan Cihampelas Kabupaten Bandung Barat.

C. Jenis dan Sumber Data 
Jenis penelitian ini yang digunakan adalah kualitatif atau naturalistik yang mengedepankan berbagai masalah di Padepokan Perisai Bathin terutama asal usul pendirian padepokan dan peserta yang mengikutinya sampai saat ini. Yang bersifat sewajarnya atau seadanya yang nyata dalam aspek kehidupan di padepokan tersebut.

Sumber data ini diperoleh dari dua sumber yaitu data primer dan data sekunder :

Data primer terdiri dari pimpinan atau ketua padepokan yaitu AA Yuli, sebagai pelatih AA Asep dan yang dilatih yaitu anggota atau peserta pengikut baik laki-laki maupun perempuan berjumlah 20.000 orang. Biasanya hanya yang aktifnya saja yang mengikuti pelatihan. Pelatih biasanya menggunakan cara dengan diisi dan adanya tes tertentu kepada anggota baru.

Data sekunder biasanya menggunakan cara dari hasil data dikumpulkan, diolah dan disajikan dari berbagai dokumentasi, buku-buku, juga ada di internet dan dari hasil penelitian yang sudah ada berupa laporan untuk dikumpulkan sebagai data yang telah ada. Hubungannya menyangkut tentang Padepokan Perisai Bathin.

D. Teknik dan Pelaksanaan Pengumpulan Data

Teknik pengumpulan data dilapangan ini menggunakan 3 pendekatan yaitu :

1. Observasi yaitu secara langsung ke lapangan melihat dan mendata sesuai dengan kenyataan keberadaan Padepokan Perisai Bathin itu baik tempat, bangunan dan posisinya yang akan melibatkan secara langsung dalam kegiatan sehari-hari agar ikut merasakan suka dukanya tentang metode dzikir dan olah napas yang mereka laksanakan. Mendapat informasi lebih lengkap sampai mengetahui makna dari setiap perilaku yang ada.

2. Wawancara yaitu melakukan interview dengan tokoh masyarakat, pimpinan dan anggota Perisai Bathin secara langsung, dimana pihak yang diajak wawancara diminta pendapat dan ideidenya tentang metode dzikir dan olah napas dalam mengungkap potensi diri di padepokan tersebut.

3. Dokumentasi yaitu mengumpulkan data dari data-data yang telah didokumentasikan dalam berbagai bentuk rekaman kejadian masa lalu yang ditulis atau dicetak berupa catatan, surat, buku harian, hal ini photo pimpinan dan pengurus serta anggota padepokan, surat ijin dari IPSI (Ikatan Pencasilat Seluruh Indonesia) termasuk bendera atau logo padepokan dan Photo peserta latihan metode dzikir dan olah napas.

\section{HASIL PENELITIAN}

A. Latar Belakang Pengembangan Potensi Diri terhadap Metode Dzikir dan Olah napas di Perguruan Perisai Bathin

Manusia terdiri dari empat unsur yaitu unsur udara, unsur air, unsur tanah dan unsur api, dari keempat unsur itu perlu dikembangkan dan diolah. Diolah oleh pernapasan untuk mendapatkan udara yang bersih. Salahsatu unsur yang terpenting adalah unsur udara maka dari unsur udara itu dijadikan sebagai dasar yang melatarbelakangi potensi diri. Kelanjutan seterusnya diolah melalui gerakangerakan hal ini oleh Padepokan Perisai Bathin dan Silat Laduni, termasuk di dalamnya gerakan olah pernapasan dan gerakan pengolahan tenaga dalam ${ }^{7}$.

Seni olah pernapasan adalah sebuah seni yang merupakan gabungan tiga unsur kekuatan yang dilakukan secara bersamaan, seperti tiga unsur waktu. Ketiga unsur itu adalah Napas, Gerak, dan Dzikir. Kita diajari bagaimana mengolah napas, gerak, dan dzikir secara bersamaan dan teratur, seperti unsur waktu. Kita diberi waktu dalam sehari semalam 24 jam dan dibagi 3 berdasarkan kegiatan kita sehari-hari, sehingga 24 jam : $3=8$ jam. Kita melakukan kegiatan secara bersamaan; 8

\footnotetext{
${ }^{7}$ A. Asep wawancara pada bulan april $2012 \mathrm{di}$ cihampelas Kab, Bandung Barat.
} 
jam kita bekerja, 8 jam kita istirahat, dan 8 jam untuk beribadah.

Latar belakang pengembangan potensi diri terhadap metode dzikir dan olah napas menurut AA Asep Ramdan Nugraha pimpinan Padepokan Silat Laduni yaitu bahwa Manusia terdiri dari 4 unsur yang sangat berhubungan dengan diri atau bathin dan jasad (lahir) yaitu; (1) Api yang identik dengan nafsu (2) Udara, identik sebagai menyejukkan qalbu atau hati tempat diamnya Ruh (3) Air identik dengan jiwa tiasa tiiseun (4) Tanah, identik dengan jasad atau makanan. Nar'um (api) sebagai atau simbol Alif. Hawa'un (udara) sebagai atau simbol Lam awal, Ma'un (Air) sebagai simbol Lam akhir. Turubun (Tanah) sebagai/simbol $\mathrm{He}$.

Dari ke empat unsur itu menghasilkan (proses) adanya Ma'rifat jika di satukan atau digabungkan dari hurufhuruf tadi sebagai simbol lafadz Allah dari itulah dinamakan silat laduni untuk mendapatkan Ma'rifat dan menghasilkan Ilmu Laduni. Sedangkan untuk mendapatkan energi, aura atau cahaya, yang dihasilkan dengan olah pernapasan yang dibarengi dengan dzikir identik dengan adanya warna yaitu merah simbolnya api, kuning simbol udara, putih atau bening simbol air dan hitam simbolnya tanah. ${ }^{8}$

Pengembangan potensi yang ada pada diri manusia yang dimaksud dengan Nafsu ada 4 bagian yaitu, nafsu amarah, nafsu lauwamah, nafsu muthma'innah, dan nafsu sufiyah atau mulhamah.

1. Nafsu amarah yaitu sumber kelakuan yang tercela dapat memancarkan sifat buruk seperti dendam, suka marahmarah.

2. Nafsu lauwamah yaitu kadang-kadang berbuat baik dan kadang-kadang berbuat buruk dan menjadi sumber penyesalan, atau menggerakkan hawa nafsu dan salah sangka.

\footnotetext{
${ }^{8}$ Wawancara dengan Pimpinan Silat Laduni pada bulan Oktober 2013
}

3. Nafsu muthma'innah yaitu jiwa yang diiringi hati yang tenang, terlepas daripada segala sifat yang tercela, dan dapat bertambah pada tingkat kesempurnaan dan akan terbuka pada kebenaran.

4. Nafsu mulhamah atau sufiyah yaitu mempunyai sifat-sifat yang baik melalui ilham dan karunia Allah seperti rendah hati, kemurahan dan tawadhu.

Untuk itulah sumber yang paling penting untuk diolah oleh pernapasan mengambil dari unsur udara sehingga unsur yang lainnya seperti unsur air, api dan tanah dapat mengikutinya dan ketika olah napas mengambil udara manusia perlu memakan makanan empat sehat lima sempurna yang diidentikan dengan tanah, dan meminum air yang bermineral begitu pula dengan olah napas yang dibarengi dengan dzikir, qalbu menjadi sejuk.

Sedangkan yang melatar belakangi pengembangan potensi diri terhadap metode dzikir dan olah napas menurut AA Yuli guru besar padepokan Perisai Bathin mengatakan bahwa pada diri manusia terdapat tiga bagian yaitu Ruh, Jiwa, dan nafsu. Selanjutnya dikatakan antara ruh dan jiwa berbeda, sedangkan jiwa dengan nafsu ada persamaannya dan nafsu terbagi pada dua bagian yaitu nafsu baik dan nafsu buruk atau jelek. Supaya manusia mendapatkan rasa tenang harus menjalankan puasa yang wajib maupun puasa sunnah ${ }^{9}$.

AA Yuli Mulyana termasuk anak ke empat dari empatbelas saudara kandung kakak beradik termasuk orang yang sangat perihatin, biasa hidup mandiri. Terutama ketika awal pernikahannya kurang mendapat perhatian kasih sayang dari orang tuanya. Karena sudah terbiasa hidup perih dan prihatin, maka dari itulah atas keprihatinannya mendapatkan petunjuk agar melaksanakan puasa selama 2 tahun berturut-turut. ${ }^{10}$

\footnotetext{
${ }^{9}$ Wawancara pada Bulan Maret 2012.

${ }^{10}$ AA Yuli Mulyana melaksanakan puasa secara berturut-turut selama 2 tahun atas petunjuk dari Raden Syahid (Sunan Kalijaga) melalui mimpi pada tahun 1990 .
} 
Orang uanya termasuk dibilang mampu atau kaya pada saat itu (sebelum melangsungkan pernikahan) karena disamping sebagai ABRI juga mempunyai perusahaan kayu pinus yang pada saat sekarang (2013) perusahaan kayu pinus tersebut diteruskan usahanya oleh adik kandung AA Yuli. Ayahnya bernama Bapak Udung (Almarhum) dan Ibunya bernama Eni Sumarni (Almarhumah) meninggal pada bulan Oktober 2013 sampai bulan sekarang mau melaksanakan peringatan meninggalnya yang ke 40 hari. Meninggalkan 14 putra putri antara lain; 1. Bapak Oding (Kota Cimahi), 2. Ibu Iis (Kota Cimahi), 3. Ibu Euis (Jakarta), 4. Bapak Yuli Mulyana (Bandung Barat Cisarua), 5. Ibu Eneng (Kota Bandung), 6. Ibu Titik (Cimahi), 7. Ateng Cimahi), 8. Ibu Lilis (Kota Bandung), 9. Bapak Ali (Jakarta), 10. Bapak Bambang (Cimahi), 11. Bapak Idan (Cimahi), 12. Ibu Dian (Kota Bandung), 13. Ibu Nia (Kota Bandung) dan 14 Riki Sudarna (Cimahi) Pada Tahun 1990 ketitisan (kedatangan) Sunan Kalijaga melalui mimpi ${ }^{11}$ di rumah tempat tinggalnya dulu di Gang Alfakah 2 disuruh puasa selama 2 tahun berturutturut, dan buka (makan) pada setiap jam 21.00 wib. (9 malam) sedangkan Sahurnya jam 2 atau jam 3 dini hari (mulai puasa).

Dari hasil puasa selama 2 tahun tersebut mendapatkan ilmu Laduni sebagai hasil (buah) dari bela diri yang menghasilkan gerakan dan ucapan sampai 87 level. Kemudian setelah menghasilkan ilmu beladiri melaksanakan lagi puasa selama 50 hari, puasa ini pelaksanaannya sama seperti puasa di bulan Ramadhan yang menghasilkan berupa Pengobatan antara lain; pengobatan orang yang digigit ular, mengobati dan mengeluarkan batu ginjal dan batu empedu yang batunya sebesar jempol, jika batunya lebih besar

\footnotetext{
${ }^{11}$ Terpilihnya AA Yuli Mulyana sebagai ketitisan Raden Syahid (Sunan Kalijaga) karena sebagai figure (gambaran) orang yang sudah terbiasa hidup perih. Sunan Kalijaga adalah murid Sunan Bonang. Wawancara bulan Oktober 2003.
}

dari jempol jari harus melalui pengobatan ke rumah sakit. Juga dari hasil puasanya AA Yuli Mulyana mendapatkan Ilmu Laduni, menurutnya bahwa Ilmu Laduni adalah hasil dari pelaksanaan/amal silat perisai bathin. laduni langsung dari Allah.

Adapun hasil dari Puasa 2 tahun yaitu menghasilkan 87 level atau tingkatan secara berangsur-angsur. Sebagai berikut ;

1. Jeblakan, dapat mementalkan musuh ;

2. Rapet omongan, musuh di depan dg ucapan rapet langsung jadi kaku seperti patung ;

3. Rapet belakang, dapat menghentikan musuh jadi kaku walaupun diserang dari belakang;

Level 1, 2 dan 3 ini termasuk mementalkan tingkat I

4. Leulah ucapan, musuh jadi leumas seperti kapas keibunan tak berdaya;

5. Tiupan rapet, ditiupkan ke musuh dari depan;

6. Hentakan rapet kaki, diucapkan hentakan rapet musuh jadi kaku;

7. Tunjukkan rapet, ditunjukkan oleh satu jari telunjuk dengan lurus musuh jadi kaku;

8. Tunjukan Leuleus, ditunjukkan oleh satu jari telunjuk dengan lurus musuh jadi leumas;

9. Gesekan rapet, telapak tangan kanan dan kiri di satukan lalu di gosokan dan dilempar ke musuh jadi rapat;

10. Gesekan leuleus, telapak tangan kanan dan kiri di satukan lalu di gosokan dan dilempar ke musuh jadi lemah badannya;

11. Gesekan Pingsan, telapak tangan kanan dan kiri di satukan lalu di gosokan dan dilempar ke musuh jadi pingsan;

12. Ampunan rapet, tangan diangkat ke musuh jadi rapat ;

13. Ampunan leuleus, tangan diangkat ke musuh jadi lemah ;

14. Ampunan pingsan, tangan diangkat ke musuh jadi pingsan ;

15. Ampunan meuntal, tangan diangkat ke musuh jadi mental ; 
16. Sintreuk rapet, tangan kanan disintreukan musuh jadi kaku;

17. Sintreuk leuleus, tangan kanan disintreukan musuh jadi lemah;

18. Sintreuk pingsan, tangan kanan disintreukan musuh jadi pingsan;

19. Sintreuk meuntal, tangan kanan disintreukan ke musuh jadi dapat memeuntalkan musuh;

20. Leuleus belakang, musuh dibelakang jadi lemah;

21. Meuntal belakang, dapat memeuntalkan musuh dari belakang;

22. Ucapan muteur, musuh jadi berputarputar ;

23. Tiupan muteur, ditiupkan ke musuh jadi berputar-putar ;

24. Jurus sapu angin, tangan digoyangkan ke musuh jadi muteur (berputar-putar) tak sadar, walaupun jumlah musuh banyak semuanya akan berputar-putar seperti disapu angin ;

25. Tiupan sinar putih, ditiupkan ke musuh langsung pingsan, cara menyembuhkannya pakai air. Baca basmallah $1 \mathrm{x}$, syahadat $1 \mathrm{x}$, Allahu Akbar 3x dan do'a (ya Allah nyuhunkeun disembuhkan). Tiupkan ke air dalam gelas lalu dipercikkan ke muka musuh hingga sadar.

26. Tiupan Sinar Merah, ditiupkan ke musuh langsung pingsan;

27. Tiupan Sinar Biru, ditiupkan ke musuh langsung pingsan ;

28. Guntur Geni;

29. Guntur Brahma dan seterusnya sampai dengan level ke $87 .{ }^{12}$

B. Tujuan Perguruan Perisai Bathin dalam mengembangkan Metode Dzikir dan Olah Napas

Tujuannya adalah untuk menyeimbangan antara manusia dengan alam sekitar. Maka dari itu manusia tidak terlepas dari hukum sunnatullah atau hukum alam. Hukum alam adalah hukum

\footnotetext{
${ }^{12}$ Penulis dalam penelitian ini hanya berhasil mendapatkan data sampai 29 level dari 87 level yang dapat diingat oleh AA Yuli Mulyana sebagai Guru Besar Padepokan Perisai Bathin. Wawancara pada hari Selasa tanggal 5 Nopember tahun 2013.
}

Allah yang berlaku di alam ini. Betapapun tinggi ilmu dan teknologi yang dapat dikembangkan manusia, tidak mungkin dapat mengubah alam itu. Apa yang dapat dilakukan manusia tidak lain adalah menelusuri dan mencoba memahami hukumhukum alam tersebut sehingga dengan izinnya, manusia kemudian dapat memanfaatkan hukum itu untuk meningkatkan derajat kehidupan yang semakin baik. positif diluar.

C. Pelaksanaan Metode Dzikir dan Olah Napas yang dilakukan oleh Padepokan Perisai Bathin

Pelaksanaan Metode Dzikir dan Olah Napas yang dilakukan oleh Perguruan Perisai Bathin antara lain;

a. Dzikir Lisan: dzikir ini diucapkan dengan lisan, ada yang melaksanakannya dengan suara keras tapi ada yang lebih suka dengan pelan-pelan ;

b. Dzikir Nafas: dalam melaksanakan dzikir ini pengucapan bacaannya seiring dengan irama keluarmasuknya udara dalam kita bernafas ;

c. Dzikir posisi: melaksanakan dzikir dalam posisi tertentu, tidak bergerak sedikitpun, dalam jangka waktu tertentu pula;

d. Dzikir qolbu atau hati: dalam dzikir qolbu bacaannya dibaca dalam hati ;

e. Dzikir Sirri atau rahasia: Proses dzikir yang satu ini adalah sangat rahasia ketika dzikir ini dilaksanakan hanya pedzikir dan yang dituju (Allah) saja yang tahu. Makhluk lain tidak ada yang bisa mengetahuinya bahkan malaikat pun tidak tahu.

D. Kebutuhan yang diperlukan dalam Metode Dzikir dan Olah Napas dalam Pengembangan Potensi Diri Manusia

Kebutuhan yang diperlukan dalam Metode Dzikir dan Olah Napas dalam pengembangan potensi diri manusia adalah kebutuhan bernapas yang baik dan teratur untuk menjaga kesehatan dan pertahanan diri. Maka dari itu bernapas sangat dibutuhkan oleh manusia untuk tetap hidup. 
Beberapa manfaat dzikrullah yang bisa dirasakan oleh orang yang selalu ingat pada Allah dimanapun ia berada antara lain:

a. Mendapat ketenangan hati dan bebas dari perasaan jengkel, kecewa, sedih, duka, dendam dan stress berkepanjangan ( Ar Raad 28);

b. Dikeluarkan dari kegelapan dan kesempitan hidup kepada cahaya terang benderang serta mendapat salam penghormatan (sholawat) dari Allah dan para MalaikatNya (Al Ahzab 43);

c. Terpelihara dan terhindar dari melakukan perbuatan keji dan mungkar (Al Ankabut 45);

d. Terpelihara dari kelicikan dan tipu daya syetan yang berusaha menyesatkan (An Nahl 99);

e. Selalu mendapat jalan keluar dari berbagai kesulitan yang datang menghadang dan mendapat rezeki dari tempat yang tidak pernah diduga, serta selalu dicukupkan semua kebutuhan hidupnya (At Thalaq 2-3);

f. Dibukakan baginya pintu kemenangan, diampuni dosanya yang lalu dan yang akan datang, ditambahkan baginya berbagai kenikmatan hidup, ditunjuki jalan yang lurus, dan diberi pertolongan dengan kekuatan yang dahsyat. ( Al Fath 1-3);

g. Selalu mendapat perhatian istimewa dari Allah dimanapun ia berada, sela-ma ia ingat pada-Nya (Al Baqarah 152);

h. Terhindar dari beban hidup yang berat dan tidak sanggup dipikul serta terhindar dari siksa dan azab yang melampaui batas (Al Baqarah 286) ;

i. Diampuni segala dosanya, dihapuskan segala kesalahannya dan diwafatkan bersama orang yang berbuat kebaikan (husnul khotimah) (Ali Imran 193);

j. Mendapat kehidupan yang baik sampai datang ajal yang telah ditetapkan (Hud 3, An-Nahl 97); k. Dibalasi dan dilipat gandakan amal kebaikannya dengan yang lebih baik dari apa yang telah mereka kerjakan (An Nahl 96-97);

1. Selalu disertai Allah dimanapun mereka berada (Al Baqarah 153, Al Hadit 4);

$\mathrm{m}$. Mendapat pertolongan dari ribuan tentara malaikat dalam menghadapi berbagai hal dan masalah didunia maupun akhirat ( Ali imran 124-125, Fushilat 30-31);

n. Dimudahkan semua urusannya dan diberi bimbingan menempuh jalan yang mudah (Al Lail 7, Al A'la);

o. Dibukakan baginya keberkahan dan pintu rahmat dari langit dan bumi (Al A'raaf 96);

p. Diwafatkan dalam keadaan baik dan disambut oleh para malaikat dengan salam penghormatan (An Nahl 32, Ar Raad 23-24, Al Ahzab 4 );

q. Mendapat kehidupan yang baik selama masa menanti dialam barzakh (Ali Imran 169);

r. Memiliki wajah yang putih berseri dihari berbangkit (Ali Imran 106107);

s. Memiliki wajah dan tubuh yang bercahaya terang dihari berbangkit ( Al Hadid 12-13 dan At Tahrim);

t. Menerima buku catatan amal dari sebelah kanan dan dimudahkan saat dihisab dan ditimbang semua amalnya (Al Haqqah 19-21);

u. Memiliki timbangan kebaikan yang lebih banyak dan berat (Al Qori'ah 6-7,Al A'raaf);

v. Diselamatkan Allah dari ganas dan panasnya api neraka (Maryam 72-73, Al Lail 17);

w. Dimasukan kedalam taman syurga dan hidup kekal selamanya disana (Az zumar 73);

Dan banyak lagi keuntungan yang didapat baik selama hidup didunia, dialam barzakh, dihari berbangkit, dipadang mahsyar dihari berhisab dan hari pembalasan. Apa yang tertulis pada butir a sampai $\mathrm{w}$ diatas adalah janji Allah yang tertulis 
didalam Qur'an. Allah pasti menepati semua janjinya, Dia tidak pernah mengingkari janji. Manfaat dzikir mengingat Allah dapat dirasakan baik ketika hidup didunia maupun diakhirat, itulah keajaiban dan kedahsyatan dzikrullah yang hanya bisa dirasakan oleh orang yang mau berdzikir mengingat Allah.

E. Hikmah (rahasia) yang Terkandung dalam Pelaksanaan Metode Dzikir dan Olah Napas.

Hikmahnya antara lain adalah dapat mententramkan jiwa dan mendapatkan tenaga dalam sebagai energi murni juga mendapatkan beberapa manfaat antara lain.

\section{Memanfaatkan Dzikir Napas}

Pengobatan dengan dzikir napas sebenarnya masuk pada kategori ruqyah. Karena mengandalkan dzikir atau wirid serta ayat-ayat Al-Qur'an. Perbedaannya dengan praktik ruqyah yang dilakukan oleh kebanyakan praktisi saat ini adalah tidak adanya peranan napas dalam pengobatan itu.

\section{Mengobati orang kesurupan:}

Saat ada orang yang kesurupan (bisa juga terhadap penderita epilepsi/ayan), maka berhadapanlah dengan penderita dan bermunajatlah kepada Allah, meminta ridha atau izin untuk memanfaatkan pemberian-Nya untuk mengobati orang yang bersangkutan.

\section{Memperkuat tulang dan gigi:}

Saat bersiwak atau menggosok gigi, maka bermunajatlah kepada Allah. Seperti biasa, tariklah napas dengan membaca Basmalah, tahan dan bacalah Ya Qawiyu Ya Matiin dan hembuskanlah di siwakmu dan mulailah bersiwak. Untuk memperkuat tulang, selain minum susu berkalsium, gunakanlah cara Islami ini.

\section{Melindungi diri dari serangan kasar maupun halus:}

Ternyata Dzikir Napas juga berguna untuk melindung diri dari serangan orang yang dengki, dengan cara bermunajat dahulu, tariklah napas dengan membaca Basmalah dalam durasi tahan, bacalah Asma Ya Allah Ya Qadiim sebanyak 3-7 kali dan hembuskan di kedua telapak tangan dan sapulah diri kita. Sebaiknya dilakukan saat akan berpergian, hendak tidur atau memasuki daerah yang tidak aman (misalnya banyak premannya). Saat kita melihat ada saudara kita dizhalimi, maka cara yang sama dapat kita gunakan. Saat menahan napas seraya memandang orang-orang yang menzhalimi (mengeroyok, memukul, dsb.) kepada saudara atau orang lain, jika anda mengepalkan tangan, maka orang-orang tersebut akan terhenti bahkan dengan izin Allah akan terpental jatuh ${ }^{13}$.

\section{SIMPULAN}

Simpulan dalam penelitian ini, secara umum merujuk pada ruang lingkup pertanyaan penelitian yang telah dirumuskan dalam bab 1, adapun jawabannya dari pertanyaan dalam penelitian ini adalah sebagai berikut:

1. Latar belakang pengembangan potensi diri terhadap metode dzikir dan olah napas yaitu Setiap manusia membutuhkan udara untuk bisa bertahan hidup. Udara inilah sebagai salah satu unsur terpenting bagi manusia hanya bagai-mana cara untuk mengolah melalui pernapasan.

2. Tujuan padepokan perisai bathin dalam mengembangkan metode dzikir dan olah napas adalah untuk menjaga keseimbangan antara dzikir dan olah napas dengan alam sebagai hukum sunatullah.

3. Pelaksanaan metode dzikir dan olah napas yang dilakukan oleh padepokan perisai bathin dan silat laduni yaitu dengan metode dzikir fersi tarekat (tasawuf), dzikir lisan, dzikir napas dan dzikir qalbu.

4. Kebutuhan yang diperlukan dalam metode dzikir dan olah napas dalam pengembangan potensi diri adalah kebutuhan akan bernapas dalam kegi-

\footnotetext{
${ }^{13}$ Wawancara dengan Pimpinan Padepokan Perisai Bathin pada bulan mei 2011
} 
atan sehari-hari perlu ditingkatkan menjadi pernapasan sempurna.

5. Hikmah yang terkandung dalam pelaksanaan metode dzikir dan olah napas adalah dapat menjalankan ibadah dengan baik dan khusu. Sehingga dapat bermanfaat bagi masyarakat.

\section{DAFTAR PUSTAKA}

Aceh, Abubakar, Pengantar Ilmu Tarekat., Ramdhani, Solo, (1993).
Agus Ahmad Safei, Memimpin dengan Hati yang selesai Jejak Langkah dan Pemikiran Dakwah Syukriadi Sambas, Pustaka Setia, Bandung, 2003.

Ali Abdul Halim Mahmud, Pendidikan Ruhani, Gema Insani, Jakarta,2000.

Depag RI, al-Qur'an dan Terjemahnya, Surya Cipta Aksara, Surabaya, 1989. Djamaludin Ancok, Fuad Nashori Suroso, Psikologi Islami, Pustaka Pelajar, Yogyakarta,2011. 